\title{
2q33.1 microdeletion syndrome
}

INSERM

\section{Source}

INSERM. (1999). Orphanet: an online rare disease and orphan drug data base. 2 q33.1 microdeletion syndrome. ORPHA:251028

2q33.1 microdeletion syndrome is a rare chromosomal anomaly syndrome, resulting from the partial deletion of the long arm of chromosome 2, with a highly variable phenotype typically characterized by severe intellectual disability, moderate to severe developmental delay (particularly speech), feeding difficulties, failure to thrive, hypotonia, thin, sparse hair, various dental abnormalities and cleft/high-arched palate. Typical dysmorphic features inlcude high, prominent forehead, down-slanting palpebral fissures and prominent nasal bridge with beaked nose. Various behavioral problems (e.g. hyperactivity, chaotic/repetitive behavior, touch avoidance) are also associated. 